\title{
Types and Degrees of Interpretive Resemblance in Translation
}

\author{
Xosé Rosales Sequeiros \\ University of Greenwich \\ xose.rosales@gre.ac.uk
}

\begin{abstract}
This articles explores one of the types of interpretive resemblance found in translation, namely, resemblance between concepts. These are cases where the concept encoded involves a resemblance relation between its literal import and the meaning it communicates, i.e. cases in which words do not literally communicate the concepts they encode. It is argued that translations are often carried out not on the basis of the concept encoded in the original text but on the basis of the actual concept communicated. This constitutes one of the sources of discrepancy found between original and target texts. In these cases, the translation encodes not what was encoded originally but (the translator's interpretation of what) the source concept was intended to communicate. There are three ways in which what is communicated by a concept may depart from what it encodes: concept narrowing, concept loosening, and echoic uses of concepts. In addition to discussing these processes in relation to translation, arguments are put forward for the existence of a further resemblance possibility: concept widening.
\end{abstract}

\section{Introduction}

In this article it is argued that discrepancies in translation are often due to the effects of interpretive resemblance between what is encoded and what is communicated. Interpretive resemblance arises when two propositional representations share their analytic and contextual implications in a given context (Wilson \& Sperber, 1988: 138). One of the main types of interpretive resemblance found in translation are resemblances between concepts, 
in particular, between the concept encoded and the concept communicated. This variety of interpretive resemblance manifests itself when the concept encoded and the meaning communicated differ in their content, and when there is a relation between the two which helps determine, via pragmatic interpretation, the concept communicated ${ }^{1}$.

The gap between what is encoded and what is communicated has significant consequences for translation. Indeed, target texts are often carried out not on the basis of the concept encoded in the original text, but rather on the basis of the related concept it communicates. As Wilson (1993a,7: 11) argues, "a word which linguistically encodes a certain concept doesn't necessarily communicate that concept". This constitutes one of the sources of discrepancy found between original and target texts. In these cases, the translator chooses to encode not what was encoded originally but (his interpretation of what) the source concept was intended to communicate.

The particular type of discrepancy that may arise in the process of translation depends on the various ways in which an encoded concept may be used to communicate a related, but different concept. It has been argued (Wilson, 1993a) that there are three ways in which what is communicated by a concept may depart from what it encodes: concept narrowing, concept loosening, and echoic uses of concepts. In what follows, each of these pragmatic processes is discussed first monolingually and then applied to translation. In addition, it is argued that there seems to be a further possibility of resemblance: concept widening, which appears to complement concept narrowing. Let us start by looking at concept narrowing.

\section{Concept Narrowing}

The pragmatic process of concept narrowing (Wilson, 1993: 7) consists in applying a concept which is true of a set of entities to a more restricted subset of those entities. Thus, the use of a concept picks out only those entities to which it is relevant to apply it. In other words, it narrows it down to a more confined number of identifiable entities, out of all the possible entities denoted by the concept. Let us illustrate this with an intralingual example: the term 'professional'. A 'professional' is someone who takes special training in the liberal arts or sciences. On the face of it, (music) teachers meet this criterion, since both their background is in a liberal art (e.g. music) and they require special training after university (e.g. in England, the PGCE: Postgraduate Certificate in Education). However, a (music) teacher is not the prototypical professional. Thus, on hearing utterance (1), the kinds of professions we envisage are, e.g. lawyers, doctors, accountants, etc.

(1) There are too many professionals in this country.

What is happening in the interpretation of this utterance is that the entities of which it is relevant to say "professional" do not include all the entities of which it is true to predicate it. As it is shown below the implications of concept narrowing for translation are important, 
as translations may be produced not on the basis of the concept encoded, but rather the concept communicated.

This difference between the concept encoded and the concept communicated may also have consequences for the truth-conditions of an utterance, i.e. for its descriptive content, as opposed to, for instance, its attitudinal content (for background on the notion of truthconditions, see Cann, 1993, ch.1). As Wilson (1993, 7:4) points out, "there are some clear cases where this sort of narrowing affects the truth conditions of the utterance, and must therefore be dealt with at the level of the proposition expressed". Thus, example (2), uttered whilst looking out into the open countryside, may have various referents:

(2) I like it here.

The referent of 'here' may be this spot, the countryside, this region, this country, etc. The particular choice made in a given context will depend on what the hearer takes the speaker to have intended. Each of those referents affects the truth-conditions of the utterance and hence they must be included in the proposition expressed, which specifies the descriptive content of the utterance (see Gutt, 1991: 24-33; Blakemore, 1992, ch.5).

In translation, the narrowing down of concepts is one of the results of the processes involved in interpreting a text. As Baker states:

[a transiator] must attempt to perceive the meanings of words and utterances very precisely in order to render them into another language. This forces us as translators to go far beyond what the average reader has to do in order to reach an adequate understanding of the text (Baker, 1992: 17 , my italics).

Part of an adequate understanding of a text is deriving the intended propositional forms of the utterances it contains. To do this the translator often has to go beyond the linguistically encoded content of the text and draw information from the context to derive a fuller propositional form. The translation will then be carried out on the basis of this complete propositional form. This means that the translator has a choice between rendering, in the target language, just the linguistic content of the source text (i.e. the words encoded in the original language) or the proposition it expressed (i.e. the full thought it was intended to communicate).

One of the sources of discrepancy between source and target texts lies precisely in the decision by a translator to encode not the linguistic content of the source text, but the proposition it expresses. Concept narrowing is often responsible for the discrepancy that arises between the encoded utterance and its propositional form. The following translation from Spanish, taken from a short story (from Lawaetz, 1972: 180-1), shows this narrowing down process, where the example involves a hotel room which is being described:

(3) El agua salía hirviendo, y eso compensaba la falta de sol y de aire.

The water from the tap was boiling hot, and this compensated for the lack of sunlight and fresh air. 
The word at issue in the Spanish original is aire, which literally means air. It seems clear that the author did not intend this word to be understood as communicating literally air. If he had intended that interpretation, the text could hardly be taken as a true description of a possible world, as it would entail that there was no air at all in the hotel room (and therefore no possibility of life). This is surely an unwanted implication. The author, therefore, must have intended to mean something else, such as a more specific type of air.

There are many types of air: polluted air, stuffy air, clean air, fresh air, etc. In this case, where the text is about a hotel, it seems reasonable to take the author to have had in mind a stuffy room and to have intended the interpretation fresh air, thus contributing a narrowed down concept to the proposition expressed. This is precisely what the translator rendered in English, i.e. the truth-conditional contribution of the concept air in this context, rather than just the concept it encodes literally. This is one of the discrepancies between the original and the target texts found in (3), which as we can see stems from translating not the literal linguistic content of the original text but what it was used to communicate.

Concept narrowing is, of course, not restricted to any particular type of translation and is a special case of the more general relevance-theoretic notion of enrichment ${ }^{2}$, which goes beyond the simple narrowing down of a literally encoded concept. The following technical example shows an original English text with its attendant Spanish translation (taken from a FUJICHROME Instructions Leaflet, in which I am assuming the English text is the original language, as it comes first and there is no Japanese version of the text):

(4) FUJICHROME 100 Film is a Daylight Type for use with light sources mentioned below.

FUJICHROME 100 es una película equilibrada para fotografiar con luz diurna y debe usarse solamente con los siguientes tipos de luz.

The concept at issue here is the Spanish solamente, which literally means only. This concept is not present in the English original. In fact, the translator of this text seems to have narrowed down the scope of the light sources intended, resulting in an enrichment of the original. This enrichment can be seen more clearly, if we look more closely at the English original.

The original text could be interpreted in any number of ways. For example, it could be construed as being qualified by "at least", "preferably", "mainly", "only", etc., as (5) shows:

(5) a. FUJICHROME 100 Film is a Daylight Type for use at least with light sources mentioned below.

b. FUJICHROME 100 Film is a Daylight Type for use preferably with light sources mentioned below.

c. FUJICHROME 100 Film is a Daylight Type for use mainly with light sources mentioned below. 
d. FUJICHROME 100 Film is a Daylight Type for use only with light sources mentioned below.

This means that there are many ways in which the scope of the light sources referred to in the text could be narrowed down. It seems probable though that, in this context, the intended propositional form is that corresponding to (5d), namely, the one that restricts the light sources to just those which are, in the original leaflet, listed immediately after the current example. It is precisely this narrowed down scope that the translator conveys linguistically in Spanish. It is important to note that there is no grammatical reason why the translator could not have been faithful to the style of the original by leaving the scope implicit, whilst still intending to communicate the same propositional form. To illustrate this point further, consider the following amended version (where there is no linguistic mention of solamente/only):

(6) FUJICHROME 100 Film is a Daylight Type for use with light sources mentioned below.

FUIICHROME 100 es una película equilibrada para fotografiar con luz diurna y debe usarse con los siguientes tipos de luz.

In this case, although there is no mention of solamente, we can still interpret it in the restrictive sense. This provides further evidence that in (4) the translator has decided to encode linguistically not just the original text, but the propositional form he derived from it. It is interesting to note that the German version of this text has been faithful to the style of the original, whilst also giving rise to the same restricted scope as in the Spanish:

(7) FUJICHROME 100 Film is a Daylight Type for use with light sources mentioned below.

Der FUIICHROME 100 ist ein Tageslichtfilm, der auffolgende Lichtquellen abgestimmt ist.

In this German example there is no reference to the scope of the light sources: it is left for the reader to infer and include in the propositional form expressed by the utterance. These examples suggest that translators adopt different styles in communicating the same propositional form. As a result, the target texts may vary in linguistic terms, but not necessarily in communicative terms (i.e. in terms of the overall content conveyed). Let us now turn to the next type of interpretive resemblance relation, namely, loose uses of concepts.

\section{Loose Uses of Concepts}

Concept loosening, which covers metaphor, is another case where the communicated concept differs from the encoded concept. In this case, what is communicated shares some 
of its implications with the original, but not all. For example, the following utterance does not communicate every implication derivable from the literally encoded concept:

(8) An idea not to be sniffed at. (taken from The Times Higher Education Supplement, 2/2/1996)

It does not, for instance, communicate the following implication (although, had it been a literal use of sniff, it would):

(9) The idea must not be smelled.

Ideas cannot be smelled. The utterance can, however, be taken to communicate the following implications:

(10) a. The idea must not be derided.

b. The idea must not be made fun of.

c. The idea must be respected...

The use of sniffed at in (8) is less-than-literal or loose. Adopting a relevance-theoretic approach in the analysis of this type of pragmatic process, the use of sniffed at would be consistent with the communicative principle proposed within relevance theory (cf. Wilson and Sperber, 1993: 287), which stipulates that processing costs and contextual effects must be balanced. In the interpretation of (8), this balance is achieved because, if the implications derived in (10) were literally spelt out, it would involve greater processing costs for the hearer than is required in interpreting (8). Examples such as (8) are said to communicate an impression, i.e. a series of weak implicatures, which could not be straightforwardly paraphrased without loss of content. Moreover, expressing them linguistically would change the style of communication from a vague and weak type to a more precise and stronger type, which may not always be desirable (e.g. in titles such as (8)) $)^{3}$. To see the overall effect of a stronger and more precise title, compare the original, loose, title in (8) to the following, more literal, title in $\left(8^{\prime}\right)$ :

(8') An idea not to be ridiculed.

Although this new version communicates a determinate, specific, and literal proposition, it does not attract our attention as much as the original, looser, title in (8), which left it more open to us to pursue our own line of interpretation and thus was more appealing (as a title).

In the case of interlinguistic communication, the differences between what is encoded and what is communicated, as a result of loose use of concepts, is another source of discrepancies found in translation. For example, the following title of a short story in Spanish is not a literal use of language (taken from Lawaetz, 1972: 180): 
(11) La puerta condenada

The condemned door (literal translation)

The term in question here is condenada (condemned). In Spanish, this term literally means to pass sentence on a person by a judge. However, what the author had in mind here was not any legal sentence passed on the door, instead he wanted to communicate some of the implications derivable from the literal concept condemned:

(12) a. The door is to be avoided.

b. The door has been left without use.

c. The door is a symbol of evil.

d. The door where horrible things have happened...

It would be much more costly, cognitively speaking, to encode every single one of these intended implications than to communicate a less-than-literal interpretation of the concept and weakly suggest all of them at the same time (by means of a single utterance). Considerations of relevance led the writer to use condenada. The translator, however, did not render the original literally in English. Instead, s/he derived the interpretation first and then, on the basis of what she took the author to have communicated, produced the following English version (Lawaetz, 1972: 181):

(13) The disused door.

This version is one of the implications of the original. In Spanish when an entity is condemned, it can be interpreted as being left without use, following the parallelism of a prisoner who is deprived of normal life. However, this implication is not necessarily the only one communicated by the author in uttering the sentence in (11). The translator has offered an English text based on the concept communicated, not on the concept encoded, by the original. By doing this, $\mathrm{s} /$ he has aliered the style. In particular, $\mathrm{s} / \mathrm{he}$ has produced a literal use of language, as opposed to a less-than-literal one. In other words, his/her utterance is a literal interpretation of the thought he wanted to communicate. It does, therefore, explicate its own propositional form, unlike (11) which does not. As a result, there is also less involvement on the part of the reader in the process of interpretation, because $s /$ he would not take as much responsibility in deriving the intended implications. In other words, there is not as much indication on the part of the translator, as there is on the part of the author, regarding the direction he foresees the interpretation to go. That is, the original author, in using a metaphor, invites readers to create their own impression of the story by the title; whereas the translator, in using a literal expression, at most can only hope to have encouraged readers to pose questions regarding the content encoded in the translated title (e.g. why is it in disuse, etc.). Moreover, the translation could be even entertained as having no implicatures at all (see Blakemore, 1992: 128), in clear contrast with the original text ${ }^{4}$. 
Another discrepancy associated with loose uses of concepts in translation arises when the interpretive resemblance found in the target text is different from that found in the source text. The following extract from the same short story discussed above exemplifies this point:

(14) De no estar allí la puerta condenada, el llanto no hubiera vencido las fuertes espaldas de la pared.

Had the door not been there, the wailing would never have overcome the strong bastion of the wall. (ibid.: 186)

The expression in question here is espaldas, which literally means (human) backs:

(15) Las fuertes espaldas de la pared.

The strong backs of the wall. (Literal translation)

The Spanish original obviously involves a loose use of the concept espalda (de la pared). In particular, it does not communicate any of the following:

(16) a. The back of the wall has a spinal cord.

b. The back of the wall is covered with skin.

c. The back of the wall is behind the chest...

What it may communicate in the current context, where the text refers to the walls of a hotel, are these other implications:

(17) a. The backs of the wall isolate guests from one another.

b. The backs of the wall protect the guests.

c. The backs of the wall resemble two humans turning their backs on each other...

In contrast to the previous example, the target English text in this case has not become more literal than the source text. Instead the translator chose to be faithful to the original loose use of language (i.e. the communicative style), but changed the metaphor (i.e. the suggested impression). The interpretive resemblance in the target text provided by the translator is not between the back of a wall and the back of a human as in the original, but rather between the bastion of a (fortification) wall and the wall itself. Thus, the type of implication the reader is encouraged to derive will be, at least, slightly different in the original and target texts. In the Spanish text the implications are about the similarities between walls and people, in particular, their backs. In the English text the similarities are between fortifications and walls, in particular, the defensive and protective role which both play. Thus, as stated above, although some of these implications will be similar, and in some cases they may even overlap, other implications will certainly differ. 
To sum up, loose uses of concepts can give rise to discrepancies between source and target texts. This is due to the fact that the concepts encoded (in these cases) do not match precisely the concepts they communicate. The gap between the two is the result of an interpretive process carried out in the search for relevance (Gutt, 1991, ch.2; Sperber \& Wilson, 1986/1995).

\section{Echoic Uses of Concepts}

A third type of discrepancy between what is encoded and what is communicated involves echoic use of language. When we use a concept echoically, we are not using it to describe some state of affairs in the world. Rather, we are attributing its use to someone else (or ourselves in the past). Hence, there is a potential gap between literal and attributed concepts, which may, as a consequence, give rise to discrepancies in communication (and, in turn, translation). To illustrate, let us look first at an intralingual example of echoic use:

(18) Peter: What did Mary say?

John: You've dropped your wallet.

John's answer can be interpreted in two ways. On the one hand, it can be used descriptively, in which case John is alerting Peter that he, at that moment in time, has dropped his wallet. In this case, John is simply describing some state of affairs before him. On the other hand, it can be used echoically, in which case John is reporting what Mary had said. In this case, John is not describing a state of affairs, or committing himself to the truth of what he has reported, but rather he is simply committing himself to the faithfulness of the report. His statement interpretively resembles what Mary had said to a relevant enough degree.

Let us consider now interlingual cases of echoic use, some of which often go unnoticed. As Hervey et al. say in relation to cultural transplantion of whole pieces of work:

Cultural transplantation [s] ..., whose extreme forms are hardly to be recognised as translations at all [my italics], ... are more like adaptations -the wholesale transplanting of the entire setting of the ST, resulting in the text being completely reinvented in an indigenous target culture setting (Hervey et al., 1995: 23).

Although Hervey et al. refer here to complete pieces of work, the same general process is found at word and sentential level. These are the levels on which the discussion below is focused.

The following example is an instance of echoic use taken from the instructions of a hair conditioning product and its back-translation from Arabic (from Baker, 1992: 35), where back-translation is the translation of the target text back into the original language:

(19) Original

For maximum effect, cover the hair with a plastic cap or towel. 
Back-translation from Arabic

For obtaining maximum effectiveness, the hair is covered by means of a "cap", that is a plastic hat which covers the hair, or by means of a towel.

The expression at issue here is the term cap and the way it has been rendered in Arabic shown in bold in the back-translation. The English term in the original is used descriptively, but in the Arabic version it is used echoically (i.e. what the English/writer call/s cap). This echoic use is spelt out by providing a definition of what is meant. Hence, the translator is using a term echoically and at the same time explaining the content of the attributed concept. Obviously, he realised that the readers would lack enough knowledge to interpret the concept, i.e. it would not give rise to cognitive effects, and decided to provide background information to achieve successful communication.

Let us consider another example. Take the following English text about a private motor museum and part of its German translation (quoted in Baker, 1992: 34):

(20) The Patrick Collection has restaurant facilities to suit every taste -from the discerning gourmet, to the Cream Tea expert.

...vom anspruchsvollen Feinschmecker bis zum "Cream-Tea"-Experten.

\section{Back-translation from German}

...from demanding gourmets to "Cream-Tea"-experts.

The translator here has decided to keep the original Cream-Tea, which in German is, arguably, an echoic use given that it mentions the English expression. That is, the interpretation in this case would be: what the English call Cream Tea. This is done overtly by virtue not only of its being a foreign word in German, but also of its being presented in inverted commas. Note that the difference between this case and the previous one is that here no spelling out of the concept is provided. It is assumed that the German readers will have the relevant information accessible to interpret the expression. In other words, they are assumed to have enough knowledge about this English institution, so as to render any explanation of its meaning unnecessary.

This type of change from descriptive use to echoic use is not always the chosen path to translating a source text. The Italian version of text (20) chooses to respect the descriptive use of language of the original, as the following extract shows (quoted in Baker, 1992: 33):

(21) ...di soddisfare tutti I gusti: da quelli del gastronomo esigente a quelli dell'esperto di pasticceria.

\section{Back-translation from Italian}

...to satisfy all tastes: from those of the demanding gastronomist to those of the expert in pastry. 
The word in question here is pasticceria, which as the back-translation shows means pastry. This is not an echoic use of language as in the German example, but a descriptive one. Hence, the translator has been faithful to the original as far as the descriptive use is concerned. Of course, the result of this decision is that the Italian text communicates something different from what the original text intended. That is, a Cream Tea expert is not the same as a pastry expert. Content has thus been sacrificed. This may also reveal the attitudes of the respective translators about the original text, where the German translator opted for a foreignisation of the target text and the Italian for a domestication (for a critique of these terms see Robinson, 1997, part 3).

In some cases, a term used echoically in one language may be used descriptively in another. This happens, particularly, when the source text includes a term which is a loan word from the target language. A case in point is the following English text, taken from the information leaflet on The Patrick Collection already mentioned:

(22) You can even dine "alfresco" in the summer on our open air terrace.

The word in question here is alfresco. This is an Italian expression which means "in the open air". However, in the English text it is used echoically, as shown by the quotation marks. The Italian translation of this text would not include an echoic use of the word, since in this language it is used descriptively.

(23) D'estate potrete anche pransare alfresco sulle nostre terraze.

In Italian, the word alfresco is used colloquially (native informant), in clear contrast with its echoic use in English, where it is used in more educated contexts and it has connotations of sophistication (which are absent in the Italian original). In more standard Italian, the expression used would be all'aperto, i.e. in the open (native informant). However, in either case the Italian text would include a descriptive use of language, as opposed to the English text which resorts to an echoic use of language.

The descriptive strategy was also used by the German translator of the text, as the following German version shows:

(24) Im Sommer können Sie auch auf der Terrasse im Freien sitzen und essen.

\section{Back-translation from German}

In the summer you can sit and eat in the open on the terrace.

As we see, the style of the German text has changed from interpretive to descriptive use of language by using in the open/im Freien. This means, amongst other things, that the attitudes that could have been communicated by the echoic use (e.g. -Italian- sophistication, etc.) are lost in the target text. Let us now turn to the last type of interpretive resemblance relation to be considered. 


\section{Concept Widening}

In addition to the three types of resemblance relation (between concepts) mentioned so far, there seems to be a further resemblance possibility: concept widening. This is the opposite case to concept narrowing and it may be possible to analyse it as a sub-case of loosening in that it applies to some objects that do not fall under the concept (see above).

Concept widening involves the communication of a concept whose meaning, in a particular context, is more general than that of the concept linguistically encoded. That is, what is communicated includes what is encoded. In translation, concept widening involves encoding a target concept whose set includes the set encoded by the source concept. It is first illustrated intralinguistically with an example, taken from the contemporary novel Sophie's World:

(25) But when these basic needs have been satisfied -will there still be something that everybody needs? Philosophers think so. They believe that man cannot live by bread alone. (Gaarder, 1991; English Translation, 1995: 12, my emphasis).

The word in question here is bread. The concept it communicates in this context seems to go beyond what it encodes. It is not communicating that philosophers believe that man cannot live by eating bread only. The issue here is not bread in particular, but food or basic needs more generally. In each of these interpretations the content of the concept bread would be included in the concept communicated (bread is food which in turn is a basic need). In this case it would be misleading to take the author to have communicated just bread. The subset relation at hand is shown in the following diagram:

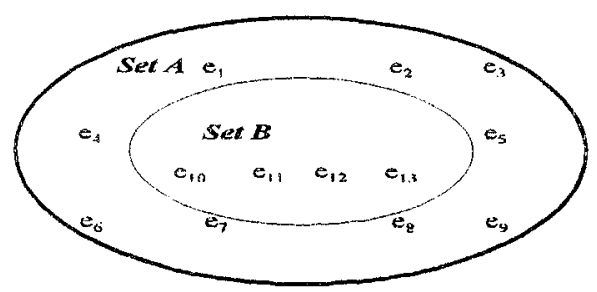

Set $A=>$ Set of entities of which it is relevant to say that they are bread. Set $B=>$ Set of entities of which it is true to say that they are bread.

This analysis, in fact, seems to be corroborated by the text that follows the extract in (25) in the novel:

(27) Of course everyone needs food. (ibid., my emphasis). 
As (27) shows, what the author had in mind was not just bread, but food (or even basic needs), in which bread itself is included.

An interlinguistic example of concept widening can be seen in the following translation from Spanish (taken from a short story in Lawaetz, 1972: 196-7):

(28) La mujer no había mentido.

The woman had deceived no one.

The original Spanish text includes the word mentido, which literally means lied. However, the translation provided here contains deceived. There is no grammatical reason why the translator could not have rendered the original text literally, as the following version shows:

(29) The woman had not lied.

The translator (as a reader) has arguably taken the author to have communicated not that the female character in the short story had lied but, more generally, that she had deceived. This interpretation is possible because lying is a sub-case of deceiving and hence there is an interpretive resemblance between the two concepts: they share some of their logical and contextual implications. It is also possible because in the story what is relevant is whether the woman is morally apt, and not so much what the moral flaw is. The widening of the concept encoded in (28) causes the discrepancy in the target version.

Another example of concept widening is the following translation of the instructions of a Hewlett-Packard print cartridge:

(30) Have highest quality output every time with this HP print cartridge.

Consiga siempre la máxima calidad de impresión con este cartucho de impresión HP. (Hewlett-Packard Co.)

The Spanish expression at hand here is siempre, which literally means always. The translator has interpreted the English expression every time in this context as meaning always, which in itself includes the meaning of every time. That is, he has widened the temporal scope of the source text in the target version (which could have included a more literal rendering of the English original in Spanish, i.e. cada vez, every time).

Thus, the widenings of concepts effected in these translations have resulted in discrepancies between source and target texts. The translator rendered the target texts on the basis not of the encoded but the communicated concepts, thereby giving rise to the differences between the two texts.

\section{Conclusion}

Interpretive resemblance between concepts underpins the gap that exists between what is encoded and what is communicated. Four possible types of interpretive resemblance have 
been considered. They explain some of the discrepancies that arise in the process of translation between the source and target texts as a result of pragmatic processing.

All these four types of discrepancy between encoding and communication are reflected firstly in the (interpretive) mediation of the translator in rendering a source text in a target language, and secondly in the resulting discrepancies between these two texts. In general, these processes may give rise to a change in the style of the text from source to target language, e.g. from inference to encoding or from interpretive use to descriptive use of language.

These cross-linguistic textual changes may have implications for judgements of acceptability in translation (for the notion of translation acceptability from a pragmatic point of view, see e.g. Rosales Sequeiros, 1998b). Acceptability judgments will be affected because what is deemed to be acceptable in one context may not be so in another. For example, a widening such as the one carried out in the translation of (28) above may be acceptable in a commercial translation of the short story in question. However, it may not be so acceptable in other situations (e.g. as part of an exam). Ultimately, acceptability judgements will be dependent on the degree to which expectations raised in the audience by the translation are met during the interpretation of the resulting target text.

\section{Notes}

1. The research discussed here belongs within a more general program of establishing the types and degrees of interpretive resemblance found in translation and the role interpretive resemblance plays in (a) clarifying and explaining the varieties of discrepancy between source and target texts and (b) the degrees of acceptability involved in translation.

2. Enrichnent is one of several pragmatic processes required to develop the bare semantic representation of an utterance into a full, truth-evaluable, propositional form (cf. Gutt, 1991:2425; Blakemore, 1992: 77ff.).

3. For a discussion of strong and weak communication see Sperber \& Wilson 1995, and Blakemore 1992.

4. It is interesting to note here that some English dictionaries (e.g. Collins Concise Dictionary Plus) quote the meaning of disused as one of the senses of condemned. This shows to what extent lexicographers list meanings which are, in fact, interpretations of the literal sense of the concepts being defined. They often provide long lists of less-than-literal interpretations of (the original) concepts, which may in time become literal meanings in their own right.

\section{Works Cited}

Baker, Mona (1992): In other words. London: Routledge.

Bassnett, Susan (1991): Translation Studies. London: Routledge.

Cann, Ronnie (1993): Formal Semantics. Cambridge: Cambridge University Press.

Carston, Robyn (1988): "Implicature, explicature, and truth-theoretic semantics". In R. Kempson, ed., Mental representations. Cambridge: Cambridge University Press, 155-182.

(1993): "Conjunction, explanation and relevance". Lingua 90:27-48.

Dagut, M.B. (1976): "Can metaphor be translated?". Babel XXII:1-22. 
Franco, Jean (ed.)(1966): Spanish Parallel Text 1. London: Penguin.

Gutt, Ernst-August (1991) Translation and Relevance: Cognition and Context. Oxford: Blackwell. . (2000, 2nd Edition) Translation and Relevance: Cognition and Context. Manchester: St. Jerome.

Hatim, Basil \& Ian Mason (1990): Discourse and the Translator. London: Longman. . (1997): The Translator as Communicator. London: Routledge.

Hervey, S., I. Higgins and L. Haywood (1995): Thinking Spanish Translation. London: Routledge.

Koefler, W. (1967): Die Theorie der literarischen Übersetzung. Munich: Fink.

Lawaetz, G. (1972): Spanish Parallel Text 2. London: Penguin.

Mounin, G. (1963): Les problèmes théoriques de la traduction. Paris: Gallimard.

Nida, E.A. (1964): Towards a Science of Translating. Leiden: Brill.

Nida, E.A. and Ch. R. Taber (1974): The Theory and Practice of Translation. Leiden: Brill.

Recanati, François (1989): "The pragmatics of what is said". Mind and Language 4:295-329.

Reiss, K. (1971): Möglichkeiten und Grenzen der Übersetzungskritik. Munich: Max Hueber.

Robinson, Douglas (1998): What is Translation? Centrifugal theories, Critical interventions. Ohio:

The Kent State University Press.

. (1997): Becoming a Translator. London: Routledge.

Rosales Sequeiros, Xosé (1995): "Interlingual Pragmatic Enrichment in Literary Translation".

Paper delivered to The Linguistic Foundations of Translation conference, University of

Liverpool, September 1995.

. (1997): "Translation Discrepancies in Galician: Hamlet". Donaire 8:62-73.

(1998a): "Interlingual Impoverishment in Translation". Bulletin of Hispanic Studies

LXXV (1):145-157.

. (1998b): "Degrees of Acceptability in Literary Transiation". Babel 44:1-14.

Santoyo, Julio César (1989): El delito de traducir. León: Secretariado de Publicaciones, Universidad de León (Spain).

Sperber, Dan and D. Wilson (1986): Relevance: Communication and Cognition. Oxford: Blackwell ( $2^{\text {nd }}$ edition: 1995).

Steel, Brian (1979): Translation from Spanish. Madrid: Sociedad General Española de Librería.

Steiner, George (1975): After Babel: Aspects of Language and Translation. London: Oxford University Press.

Stockwell, R. P., D. Bowen and J.W. Martin (1965): The grammatical structures of English and Spanish. Chicago: The University of Chicago Press.

Torre, Esteban (1994): Teoria de la traducción literaria. Madrid: Editorial Síntesis.

Vinay, J.-P. \& J. Darbelnet (1958): Stylistique Comparée du Français et de l'Anglais. London: George G. Harrap \& Co.

Wilson, Deirdre (1993a): "Philosophy of Language". Lecture Notes 1993-1994, Dept. of Linguistics, University College London. . (1993b): "Varieties of non-truth-conditional meaning", MS.

Wilson, Deirdre and D. Sperber (1993a): "Linguistic form and relevance". Lingua 90:1-25. . (1993b): "Relevance and time". UCL Working Papers in Linguistics 5: 277-298. 